\title{
Dynamic Coefficients Identification of Water-Lubricated Hybrid Bearings Used in High-Speed Spindles with Different Excitation Methods
}

\author{
Lin Wang, ${ }^{1}$ Xianzhi Xiong, ${ }^{2}$ and Hua $\mathrm{Xu}^{3}$ \\ ${ }^{1}$ School of Mechanical Engineering, Northwestern Polytechnical University, Xian 710072, China \\ ${ }^{2}$ Xian High Voltage Apparatus Research Institute Co., Ltd., Xian 710077, China \\ ${ }^{3}$ Key Laboratory of Education Ministry for Modern Design and Rotor-Bearing System, Xian Jiaotong University, Xian 710049, China
}

Correspondence should be addressed to Lin Wang; wanglin@nwpu.edu.cn

Received 11 January 2017; Revised 5 March 2017; Accepted 14 March 2017; Published 26 March 2017

Academic Editor: Evgeny Petrov

Copyright (c) 2017 Lin Wang et al. This is an open access article distributed under the Creative Commons Attribution License, which permits unrestricted use, distribution, and reproduction in any medium, provided the original work is properly cited.

\begin{abstract}
Rotor stability and rotation accuracy, which are highly dependent on the dynamic coefficients of supporting hybrid bearings, are two important issues of high-speed water-lubricated spindles. To improve the spindles' performance, the dynamic coefficients of high-speed water-lubricated hybrid bearings were experimentally identified by the noncontact harmonic excitation method and the additional unbalance excitation method, respectively. Comparisons between experimental results and theoretical predictions were made. The experimental technique and the identification model were validated to be effective. Besides, the influence of supply pressure and rotating speed on dynamic coefficients was also presented. As for different operating conditions, valuable guides were provided to investigate the dynamic performance of high-speed and ultra-high-speed spindles.
\end{abstract}

\section{Introduction}

For the advantages of low temperature rise, high rotating speed, and long life-span, water-lubricated hybrid bearings have been used in high-speed machine tools. But some technical problems caused by high speed and compact structure of spindle system, such as rotor stability and rotation accuracy, are yet to be resolved when water-lubricated hybrid bearings are used in ultra-high-speed and ultrahigh-precision machining tools. Rotor stability and rotation accuracy of high-speed spindles are highly dependent on the dynamic coefficients of supporting bearings, especially for the stiffness coefficients. Chen et al. [1] investigated the effect of eccentricity ratio on the dynamic and static characteristics of a hydrostatic spindle for machine tools. They concluded that the machining accuracy is highly affected by the bearing stiffness. Hu et al. [2] found that the instability resulting from oil whirl gets weak as the bearing stiffness increases.

Theoretical studies with complicated models have been conducted to investigate the dynamic performance of water-lubricated hybrid bearings [3-7]. With the increasing demand for high precision and high speed of spindles, more accurate values of bearing dynamic coefficients are necessary for proper design and operation of high-speed spindles. However, theoretical predictions usually introduce errors resulting from different assumptions and simplifications. Thus, experimental investigation is necessary to find out the key design parameters of high-speed rotor-bearing system [8-10].

Dynamic coefficients of water-lubricated hybrid bearings have been experimentally investigated by the inverse method $[11,12]$, in which the exciting force is applied on the moving bearing housing. However, in the real operating conditions of high-speed spindles, the bearing clearance is very small, and thus the bearing housing has to be held rigidly with a rotating rotor. In this case, the exciting force must be applied on the moving spindle. Therefore, the exciting technique and identification model for conditions of applying force on high-speed rotor need to be developed, and the influence of 


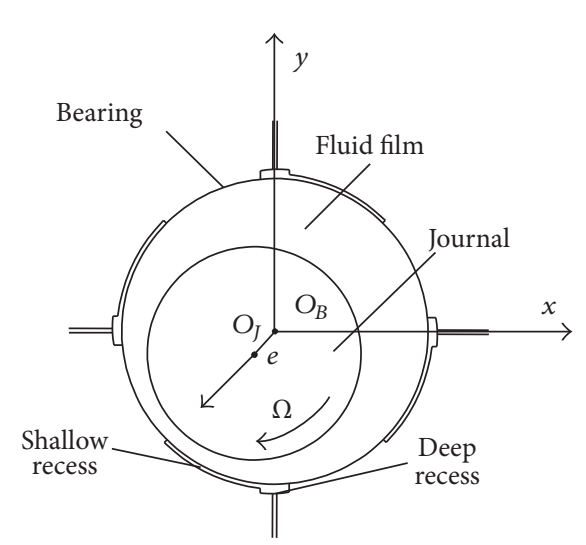

(a)

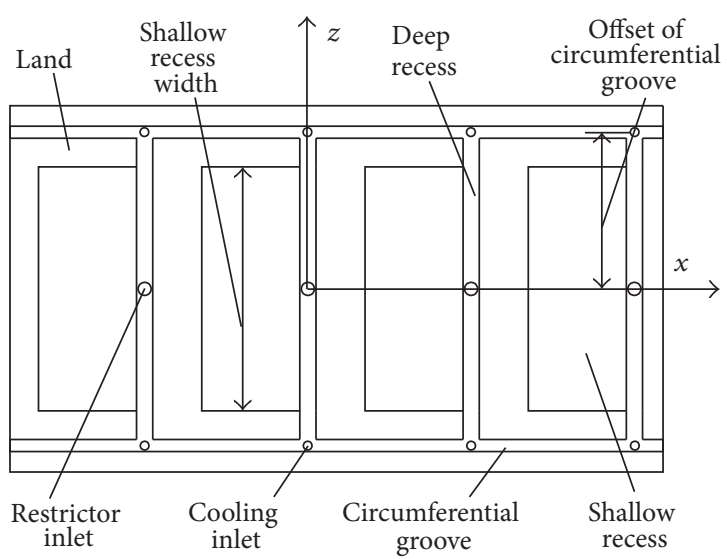

(b)

FIGURE 1: Structure of the water-lubricated hybrid bearing.

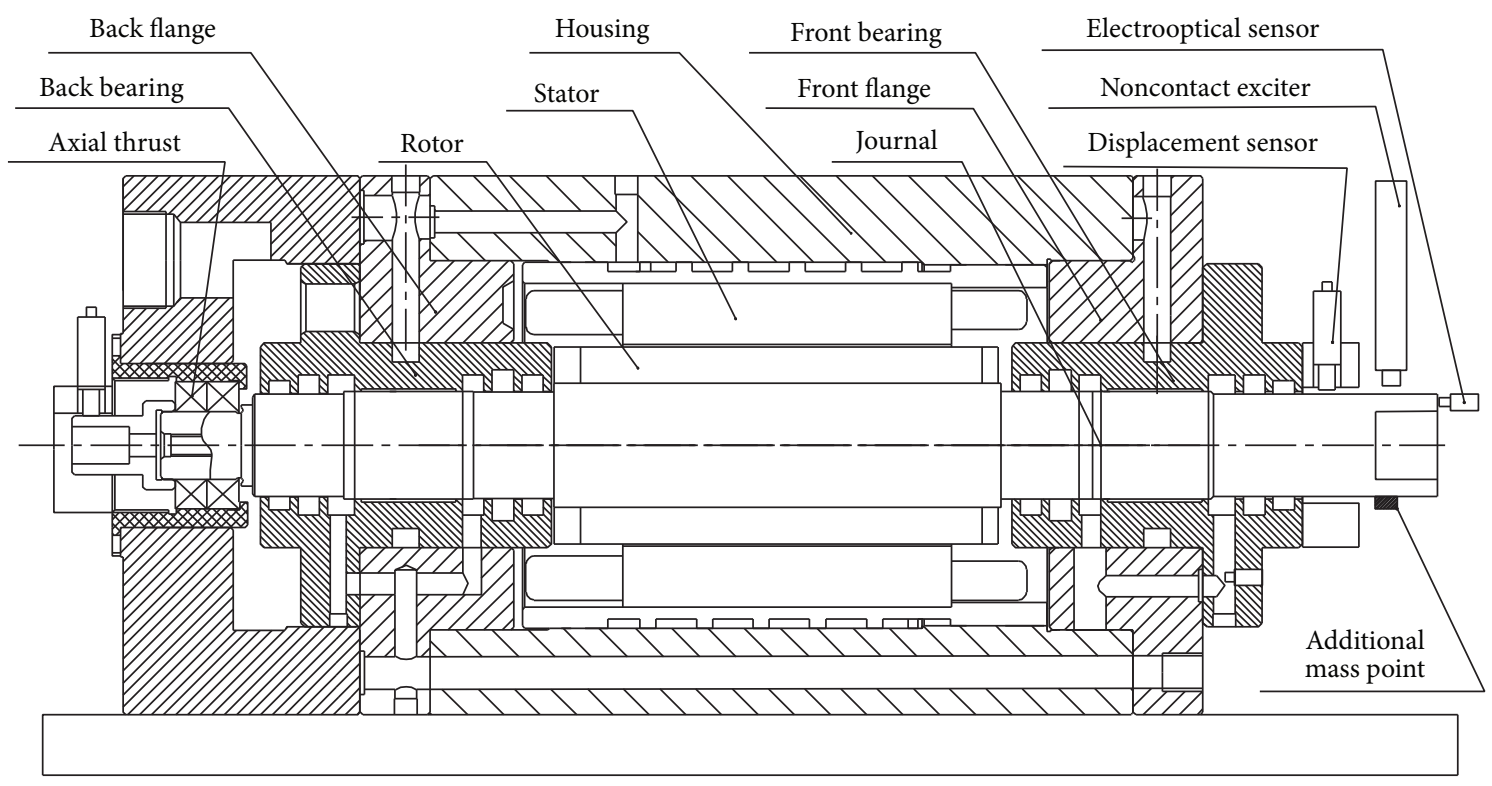

Figure 2: General view of the high-speed spindle system.

water supply pressure and spindle rotating speed on bearing performance also need to be investigated.

Thus, a water-lubricated hybrid bearing with circumferential grooves and stepped recesses was firstly proposed by the authors [13] (see Figure 1). Then, a high-speed spindle test rig was constructed [10] (see Figure 2), which uses the waterlubricated hybrid bearings as radial support. In this study, the noncontact harmonic excitation method and the additional unbalance excitation method are firstly used to identify the dynamic coefficients of high-speed water-lubricated hybrid bearings with circumferential grooves and stepped recesses.

There are different excitation methods used for parameter identifications $[12,14,15]$. The noncontact exciters have flexibility in force applications, such as sinusoidal, unidirectional, and pseudorandom excitation force [16-20]. Arumugam et al. [21] identified the stiffness and damping coefficients of tilting pad and cylindrical journal bearings using a noncontact electromagnetic exciter. Frequency response functions were obtained from the experimental measurements and the finite element method, and then bearing coefficients were calculated with a least squares method. Sudheer Kumar Reddy et al. [22] investigated the stiffness and damping coefficients of tilting pad journal bearings with small $L / D$ ratios using the noncontact excitation method. The experimental results generally showed a good agreement with the theoretical values for different $L / D$ ratios. Bediz et al. $[23,24]$ designed an electromagnetic exciter for model testing of miniature high-speed spindles. However, the noncontact exciters are 
rarely used for identifying dynamic coefficients in high-speed conditions.

The additional unbalance excitation method does not need too much space and equipment; thus it can determine the bearing dynamic coefficients with very low cost [25]. Compared with the rotor mass, the additional unbalance mass is so small that its influence on the rotor natural frequency response can be ignored. The power of the unbalance responses is concentrated at the rotating frequency, so the signal/noise ratio in frequency domain is high at the rotating frequency. It is very suitable for the excitations used in high-speed conditions. However, the additional unbalance mass usually leads to circular shaft orbit for isotropic/nearly isotropic bearings $[10,12]$, which will result in the ill-posed matrix inversion problem.

In this study, the dynamic coefficients of water-lubricated hybrid bearings are identified by the noncontact harmonic excitation method and the additional unbalance excitation method, respectively. Theoretical results of the same bearing are obtained by a thermal-hydrodynamic analysis model [13]. Then, the experimental results are compared with the theoretical results. Besides, the influence of operating parameters, such as water supply pressure and spindle rotating speed, on dynamic coefficients is also experimentally investigated.

\section{Test Rig and Identification Model}

As shown in Figure 1, the water-lubricated hybrid bearing has four stepped recesses and two symmetric circumferential grooves. Every stepped recess is consisted of a deep recess and a shallow recess. Two circumferential grooves and relevant cooling inlets are set symmetrically on both axial lands of bearing surface. The hybrid bearing has a diameter of $40 \mathrm{~mm}$ with an $L / D$ ratio of one. Detailed bearing structure parameters can be found in the authors' previous studies $[10,13]$.

Figure 2 presents the general view of the high-speed spindle system. The spindle is supported by two identical hybrid bearings and driven by a high-speed asynchronous motor. The raw rotor of this motor is placed on the journal and the wound stator of this motor is mounted on the inside surface of bearing housing.

The water-lubricated hybrid bearing test rig for identifying dynamic coefficients consisted of the high-speed spindle part and the noncontact exciter part as shown in Figure 3. Radial excitation force is applied either by the noncontact exciter [26] or by attaching an imbalance mass. As the spindle structure is compact, the noncontact exciting force and the additional unbalance force are applied on the same position of the shaft end.

The rotor is discretized into $n$ nodes, and the degree of freedom of the rotor is $4 n$. $m$ nodes corresponding to the bearing are called bearing nodes. There are two bearing nodes in this paper. The highest operating seed is 30,000 r/min while the first-order critical speed is more than $60,000 \mathrm{r} / \mathrm{min}$, so the rotor is assumed to be rigid.

The motion equation of this rotor-bearing system resulting from translational vibration is [12]

$$
\begin{aligned}
M & \{\ddot{u}\}+C\{\dot{u}\}+K\{u\} \\
& =\left\{f_{\mathrm{ec}}\right\} \cos \omega t+\left\{f_{\mathrm{es}}\right\} \sin \omega t+\left\{f_{b}(t)\right\},
\end{aligned}
$$

where $M$ is the mass matrix, $C$ is the damping matrix, $K$ is the stiffness matrix, $f_{\mathrm{ec}}$ and $f_{\mathrm{es}}$ are the cosine and sine components of the exciting force, $f_{b}(t)$ is water film force, $\omega$ is angular frequency of the exciting force, and $u$ and its derivatives refer to the displacements, velocities, and accelerations of the journal.

The linear model of water film force is expressed as follows:

$$
\left\{f_{b}(t)\right\}=-K_{b}\{u\}-C_{b}\{\dot{u}\}
$$

where $K_{b}$ and $C_{b}$ are the stiffness and damping matrices of water film.

Substituting (2) into (1) yields

$$
M\{\ddot{u}\}+\widetilde{C}\{\dot{u}\}+\widetilde{K}\{u\}=\left\{f_{\text {ec }}\right\} \cos \omega t+\left\{f_{\text {es }}\right\} \sin \omega t,
$$

where $\widetilde{K}=K+K_{b}, \widetilde{C}=C+C_{b}$.

The journal displacements can be expressed as

$$
\{u\}=\left\{u_{c}\right\} \cos \omega t+\left\{u_{s}\right\} \sin \omega t .
$$

Substituting (4) into (3) yields

$$
\left(\widetilde{K}-\omega^{2} M+i \omega \widetilde{C}\right)\{u\}=\left\{f_{\mathrm{e}}\right\},
$$

where $\{u\}=\left\{u_{c}\right\}-i\left\{u_{s}\right\},\left\{f_{\mathrm{e}}\right\}=\left\{f_{\mathrm{ec}}\right\}-i\left\{f_{\mathrm{es}}\right\}, i=\sqrt{-1}$.

Or

$$
E\{u\}=\left\{f_{\mathrm{e}}\right\}-H\{u\}
$$

where $E=K_{b}+i \omega C_{b}, H=K+i \omega C-\omega^{2} M$.

Let

$$
\{u\}=\left\{u_{A}, u_{B}, u_{C}\right\}^{T},
$$

where $\left\{u_{A}\right\}$ is $2 m \times 1$ complex vector of the horizontal and vertical displacements at the bearing nodes; $\left\{u_{B}\right\}$ is $2 m \times 1$ complex vector of the horizontal and vertical displacements at the displacement measurement nodes; $\left\{u_{C}\right\}$ is $(4 n-4 m) \times 1$ complex vector of the horizontal and vertical displacements of the other nodes.

Substituting (7) into (6) yields

$$
\left[\begin{array}{ccc}
E_{A} & 0 & 0 \\
0 & 0 & 0 \\
0 & 0 & 0
\end{array}\right]\left\{\begin{array}{l}
u_{A} \\
u_{B} \\
u_{C}
\end{array}\right\}=\left\{\begin{array}{l}
f_{A} \\
f_{B} \\
f_{C}
\end{array}\right\}
$$

$$
-\left[\begin{array}{lll}
H_{A A} & H_{A B} & H_{A C} \\
H_{A B} & H_{B B} & H_{B C} \\
H_{A C} & H_{B C} & H_{C C}
\end{array}\right]\left\{\begin{array}{l}
u_{A} \\
u_{B} \\
u_{C}
\end{array}\right\} .
$$




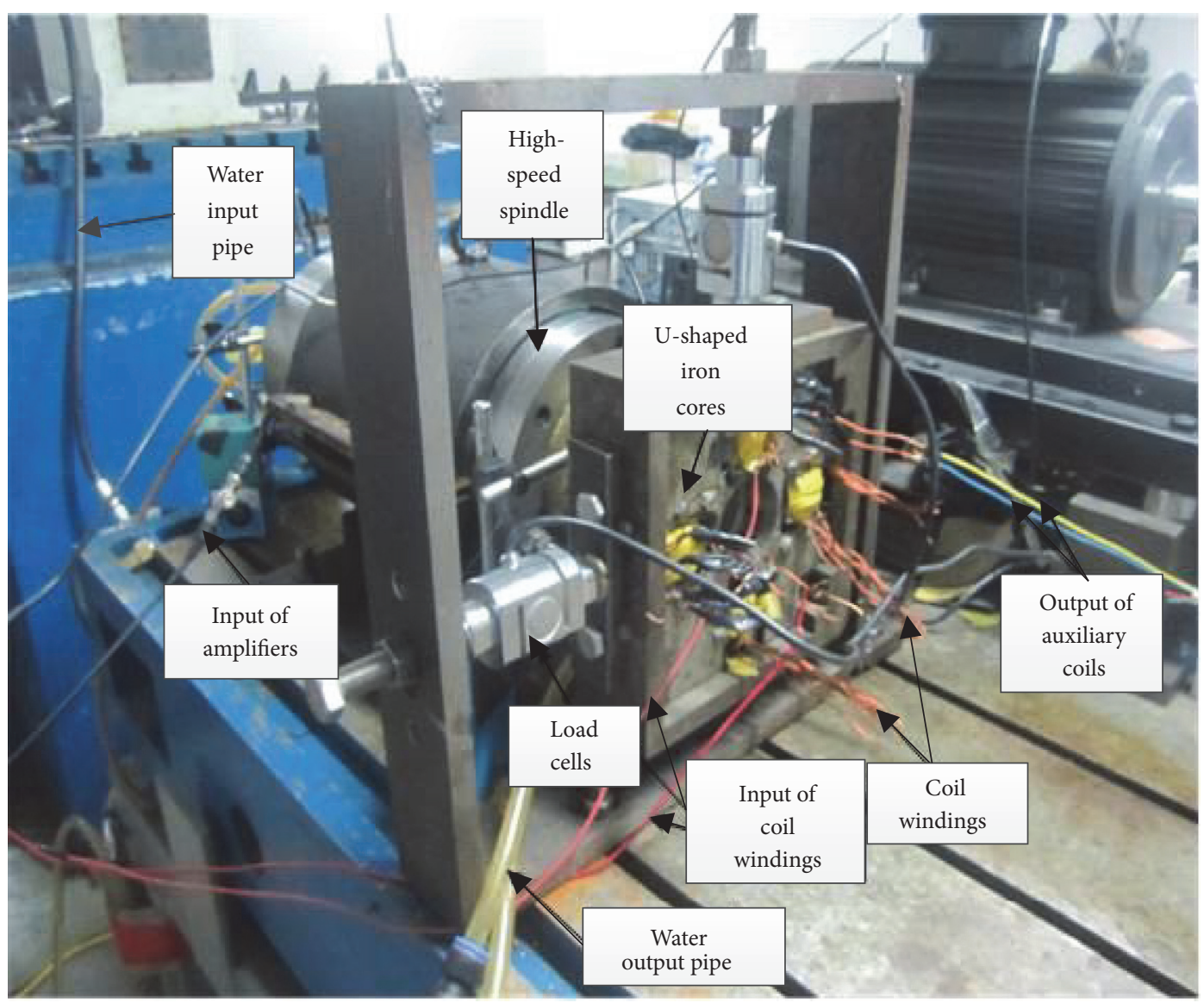

FIGURE 3: Schematic of the test rig for identifying dynamic coefficients.

Then we can get

$$
\begin{aligned}
{\left[E_{A}\right]\left\{u_{A}\right\}=} & \left\{f_{A}\right\}-\left[H_{A A}\right]\left\{u_{A}\right\}-\left[H_{A B}\right]\left\{u_{B}\right\} \\
& -\left[H_{A C}\right]\left\{u_{C}\right\}
\end{aligned}
$$

where $E_{A}$ is $2 m \times 2 m$ diagonal matrix constituting of the stiffness and damping coefficients of water film.

$\left\{u_{A}\right\}$ and $\left\{u_{C}\right\}$ can be expressed by matrix transformation from (8):

$$
\left\{\begin{array}{l}
u_{A} \\
u_{C}
\end{array}\right\}=\left[\begin{array}{ll}
H_{B A} & H_{B C} \\
H_{C A} & H_{C C}
\end{array}\right]^{-1}\left\{\begin{array}{l}
f_{B}-H_{B B} u_{B} \\
f_{C}-H_{C B} u_{B}
\end{array}\right\} .
$$

The exciting force is applied neither on the bearing nodes nor on the displacement measurement nodes, so $\left\{f_{A}\right\}=$ $\left.\{0,0, \ldots, 0\}^{T}\right|_{2 m \times 1},\left\{f_{B}\right\}=\left.\{0,0, \ldots, 0\}^{T}\right|_{2 m \times 1}$. The left side of (9) is then determined by $\left\{u_{B}\right\}$ and $\left\{f_{C}\right\}$.

Thus, (9) can be transformed into

$$
E_{A}\left\{u_{A}\right\}=-H_{A A} u_{A}-H_{A B} u_{B}-H_{A C} u_{C}=G\left(u_{B}, f_{C}\right),
$$

where

$$
\begin{aligned}
E_{A} & =\left[\begin{array}{lll}
E_{1} & & \\
& \ddots & \\
& & E_{m}
\end{array}\right], \\
E_{j} & =\left[\begin{array}{ll}
K_{x x} & K_{x y} \\
K_{y x} & K_{y y}
\end{array}\right]^{(j)}+i \omega\left[\begin{array}{ll}
C_{x x} & C_{x y} \\
C_{y x} & C_{y y}
\end{array}\right]^{(j)}, \\
& j=1,2, \ldots, m .
\end{aligned}
$$

In (11), $\left\{u_{B}\right\}$ can be directly measured; $\left\{u_{A}\right\}$ can be calculated from $\left\{u_{B}\right\} ; H_{i j}(i, j=A, B)$ are complex matrices directly estimated based on parameters of the rotor; $\left\{f_{C}\right\}$ is $(4 n-4 m) \times 1$ complex force vector including the exciting force, which is controlled by the noncontact electromagnetic exciter or the additional unbalance mass.

There are 16 unknown coefficients in (11). Either the noncontact harmonic excitation method or the additional unbalance excitation method needs two excitations on the rotor to determine all 16 linear dynamic coefficients. Running the rotor three times, including once with nothing and twice with two different excitation forces, can result in 16 linear equations which are sufficient to get all 16 coefficients. 
The experimental procedures are as follows.

(1) Running the rotor at speed $\Omega$ and sampling and saving the optical sensor signal and rotor's initial unbalance response $\left\{u_{A 0}\right\}$, then (11) becomes

$$
E_{A}\left\{u_{A 0}\right\}=G\left(u_{B 0}, 0\right) .
$$

(2) Keeping the rotor running at the same speed, applying a horizontal exciting force on the rotor (or attach the unbalance mass $m_{1}$ on the rotor), and recording the vibration displacements response $\left\{u_{A 1}\right\}$ and the exciting force $\left\{f_{C 1}\right\}$, then (11) becomes

$$
E_{A}\left\{u_{A 1}\right\}=G\left(u_{B 1}, f_{C 1}\right) .
$$

(3) Keeping the rotor running at the same speed, applying a vertical exciting force on the rotor (or attach the unbalance mass $m_{2}$ on the rotor), and recording the vibration displacements response $\left\{u_{A 2}\right\}$ and the exciting force $\left\{f_{C 2}\right\}$, then (11) becomes

$$
E_{A}\left\{u_{A 2}\right\}=G\left(u_{B 2}, f_{C 2}\right) .
$$

(4) Eliminating the initial unbalance of rotor by subtracting (13) from (14) and (15),

$$
\begin{aligned}
& E_{A}\left\{u_{1}\right\}=G\left(u_{B 1}, f_{C 1}\right)-G\left(u_{B 0}, 0\right), \\
& E_{A}\left\{u_{2}\right\}=G\left(u_{B 2}, f_{C 2}\right)-G\left(u_{B 0}, 0\right),
\end{aligned}
$$

where $U=\left[\left\{u_{1}\right\},\left\{u_{2}\right\}\right]=\left[\left\{u_{A 1}\right\}-\left\{u_{A 0}\right\},\left\{u_{A 2}\right\}-\left\{u_{A 0}\right\}\right]$.

(5) Repeating the above procedures with different rotation speed, then we can get different dynamic coefficients.

The influence of exciting force on rotor parameter and bearing coefficients is neglected. Thus, the following equation can be obtained:

$$
E_{A} U=G,
$$

where $G=\left[G\left(u_{1}, f_{1}\right), G\left(u_{2}, f_{2}\right)\right]=\left[G\left(u_{B 1}, f_{C 1}\right)-G\left(u_{B 0}, 0\right)\right.$, $\left.G\left(u_{B 2}, f_{C 2}\right)-G\left(u_{B 0}, 0\right)\right]$.

Finally, the matrix $E_{A}$ can be calculated by

$$
E_{j}=G_{j} U_{j}^{-1} \quad(j=1,2),
$$

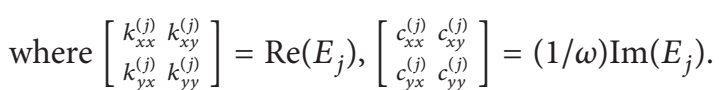

To experimentally obtain the dynamic coefficients, it is important to select the amplitude of exciting force. The electromagnetic force is mainly determined by the input current and the air gap between armature and iron cores. Compared with 3,000 r/min condition, the electromagnetic force reduces by half when the rotating speed increases to $30,000 \mathrm{r} / \mathrm{min}$ [26]. It needs to increase the input current to meet the requirement for larger exciting force. However, to avoid high power loss of iron core and amplifier, the input current is limited. On the other hand, the journal vibration increases with rotating speed, which will lead to rub between armature and iron cores when the air gap is too small.
Thus, in the first stage, the noncontact harmonic excitation method is used. Based on the characteristics of noncontact exciter, the dynamic coefficients are determined under two rotating speeds $(6,000 \mathrm{r} / \mathrm{min}$ and $9,000 \mathrm{r} / \mathrm{min})$. Subjected to the power of amplifier of the noncontact exciter, the exciting frequency can not be too high, so two exciting frequencies $(4 \mathrm{~Hz}$ and $60 \mathrm{~Hz}$ ) are chosen, and the amplitude of exciting force is about $28 \mathrm{~N}$. If the supply pressure is lower than 1.0 MPa, shaft seizing is easy to occur; while the supply pressure is higher than $3.0 \mathrm{MPa}$, it will lead to sealing failure, and water will leak to the motor. Thus, three supply pressures (1.2 MPa, 1.5 MPa, and 1.8 MPa) are used for the thought of operation safety and cost economics.

In the second stage, the additional unbalance excitation method is used. The exciting force resulting from the additional unbalance mass $\left(m_{1}=1.7 \mathrm{~g}, m_{2}=3.0 \mathrm{~g}\right)$ is determined by rotating speed. To avoid affecting the dynamic performance of shaft, the additional unbalance mass is usually very small. If the rotating speed is low, the additional unbalance mass can not excite enough displacement disturbances. Thus, to simulate the real operating condition, the dynamic coefficients are determined with $2.5 \mathrm{MPa}$ supply pressure and different rotating speeds $(9,000 \mathrm{r} / \mathrm{min}$ to $24,000 \mathrm{r} / \mathrm{min})$.

\section{Results and Discussion}

Based on the above two excitation methods, dynamic coefficients of the front bearing are identified and compared with theoretical results. The theoretical results and their geometry parameters are obtained by a thermal-hydrodynamic analysis model from the authors' previous study $[10,13]$.

Figure 4 indicates the stiffness results of noncontact harmonic excitation. The direct stiffness coefficients increase with water supply pressure and spindle rotating speed owing to the hydrostatic effect and the hydrodynamic effect, respectively. The discrepancies of experimental results between $4 \mathrm{~Hz}$ condition and $60 \mathrm{~Hz}$ condition are not more than $25 \%$. The maximum errors between the experimental results of $60 \mathrm{~Hz}$ condition and theoretical results are $19 \%\left(k_{x x}\right.$ of $\left.6,000 \mathrm{r} / \mathrm{min}\right)$, $25 \%$ ( $k_{x x}$ of $9,000 \mathrm{r} / \mathrm{min}$ ), $22 \%$ ( $k_{y y}$ of $6,000 \mathrm{r} / \mathrm{min}$ ), and $11 \%$ ( $k_{y y}$ of $9,000 \mathrm{r} / \mathrm{min}$ ), respectively.

The cross stiffness coefficients vary slightly with water supply pressure, because they are mainly affected by the hydrodynamic effect. The cross stiffness coefficients of theoretical results increases with rotating speed, while those of experimental results show few discrepancies. Besides, the theoretical results are about four to six times higher than the experimental results.

Figure 5 presents the damping results of noncontact harmonic excitation. It is shown that the experimental results of $60 \mathrm{~Hz}$ condition are much more stable than those of $4 \mathrm{~Hz}$ condition. The theoretical results and the experimental results of $60 \mathrm{~Hz}$ condition show a similar variation trend: The damping coefficients are nearly constant as the increase of supply pressure and rotating speed. The direct damping coefficients of theoretical results are 2.5 times $\left(d_{x x}\right)$ and 1.5 times $\left(d_{y y}\right)$ higher than those of experimental results of $60 \mathrm{~Hz}$ condition, respectively. 


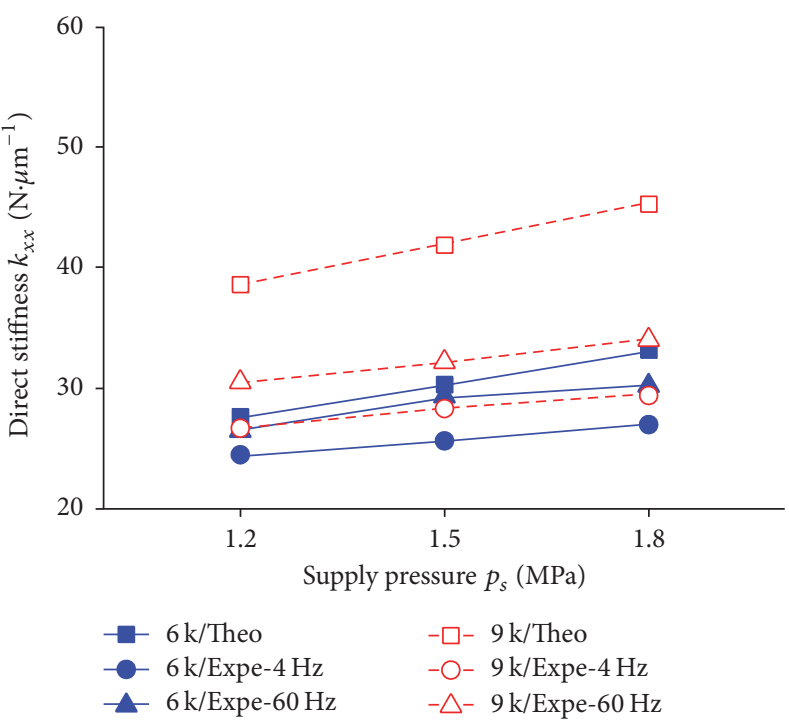

(a) Direct stiffness, $k_{x x}$

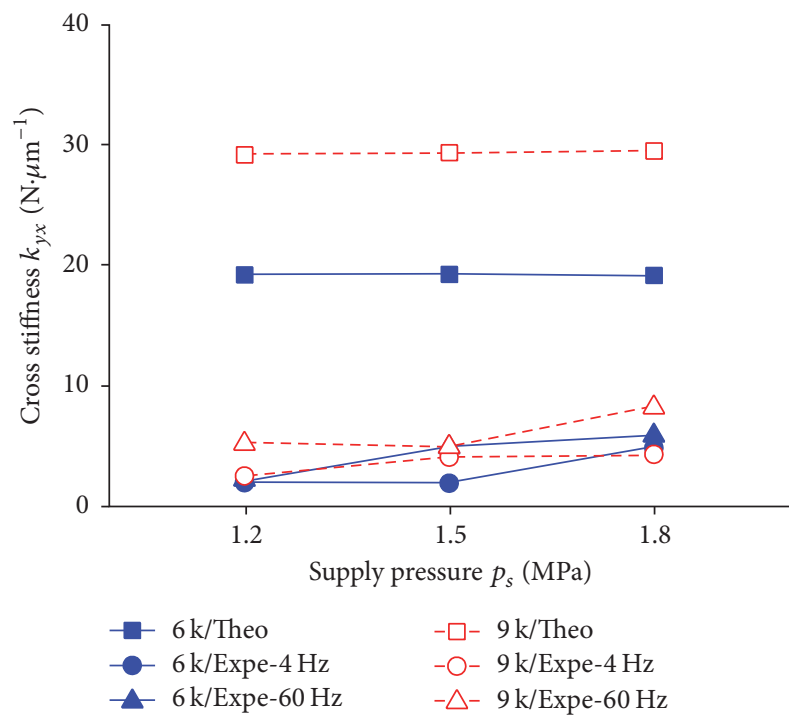

(c) Cross stiffness, $k_{y x}$

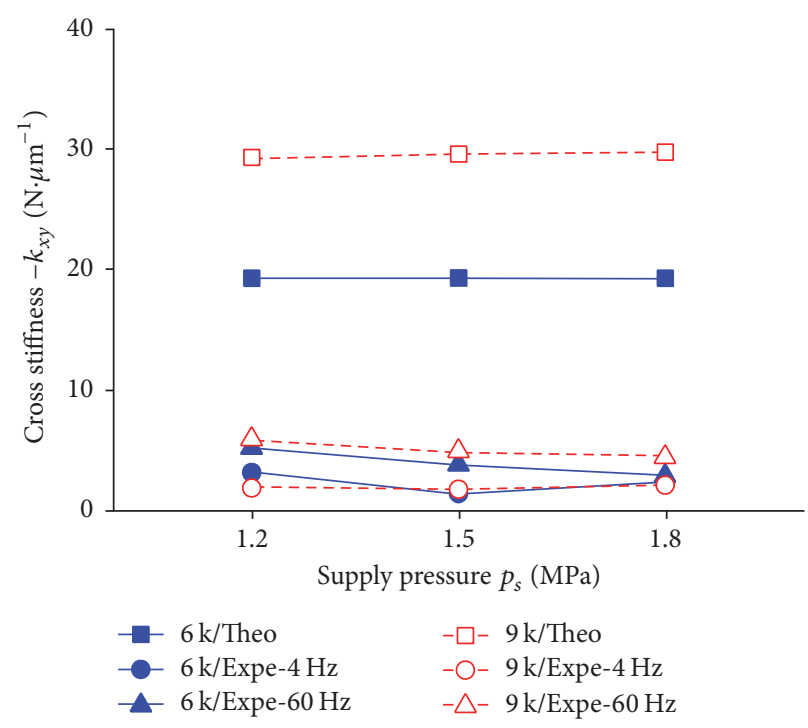

(b) Cross stiffness, $-k_{x y}$

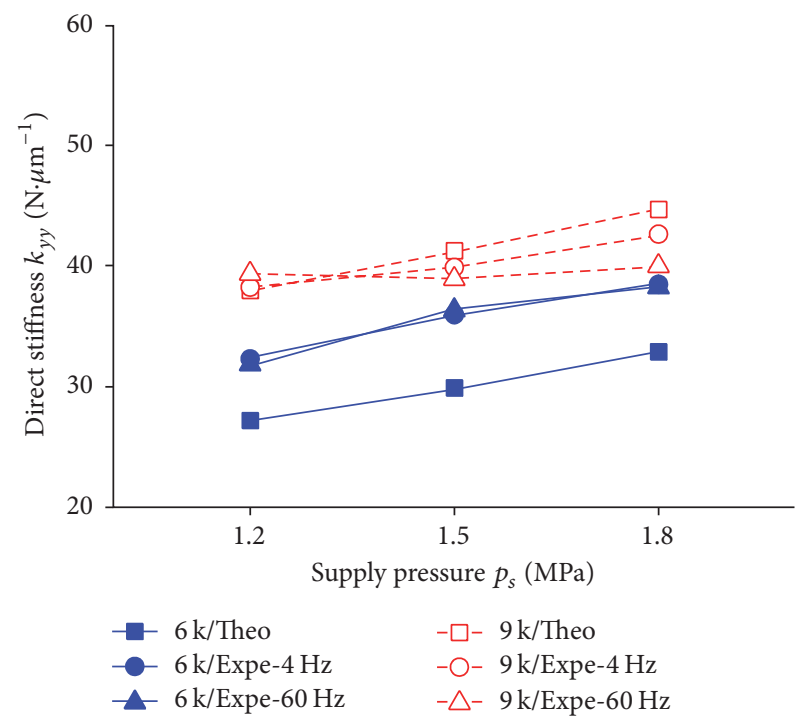

(d) Direct stiffness, $k_{y y}$

Figure 4: Comparative results of the stiffness coefficients by noncontact harmonic excitation: two rotating speeds $(6,000 \mathrm{r} / \mathrm{min}$ and $9,000 \mathrm{r} / \mathrm{min}$ ), three supply pressures (1.2 MPa, 1.5 MPa, and 1.8 MPa), and two exciting frequencies $(4 \mathrm{~Hz}$ and $60 \mathrm{~Hz})$.

It can be seen from Figures 4 and 5 that the direct stiffness coefficients have a better agreement than the cross stiffness coefficients between theoretical results and experimental results, especially for the $60 \mathrm{~Hz}$ condition. As for the damping coefficients, the experimental results of $60 \mathrm{~Hz}$ condition have a better coherence with the theoretical results. Phase errors are introduced during the measurement, and the test of lower excitation frequency is more sensitive to the phase errors, so a higher excitation frequency is preferred to get better results for bearing coefficients identification.

Figure 6 shows the stiffness results of additional unbalance excitation. Both experimental results and theoretical results indicate the same trend that the stiffness coefficients increase with rotating speed. The direct stiffness coefficients of experimental results are smaller than those of theoretical results for most cases, while the cross stiffness coefficients of experimental results are larger than or similar to those of theoretical results.

Figure 7 presents the damping results of additional unbalance excitation. It can be seen that the direct damping coefficients of experimental results have the same order of magnitude as those of theoretical values, while the cross damping coefficients of experimental results are larger than those of theoretical values by nearly two orders of magnitude.

As for the additional unbalance excitation method, the accuracy of identified dynamic coefficients is usually affected 


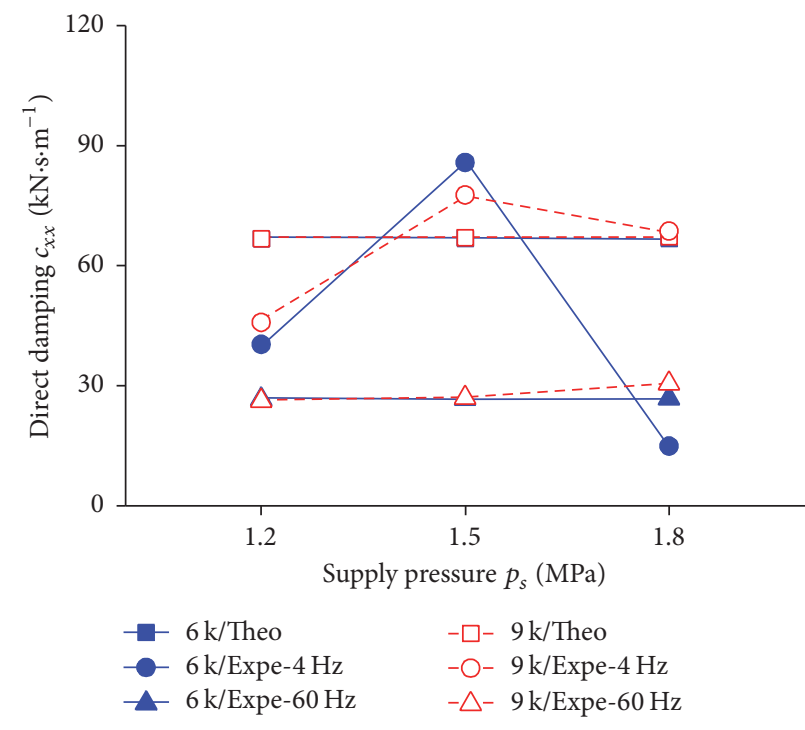

(a) Direct damping, $c_{x x}$

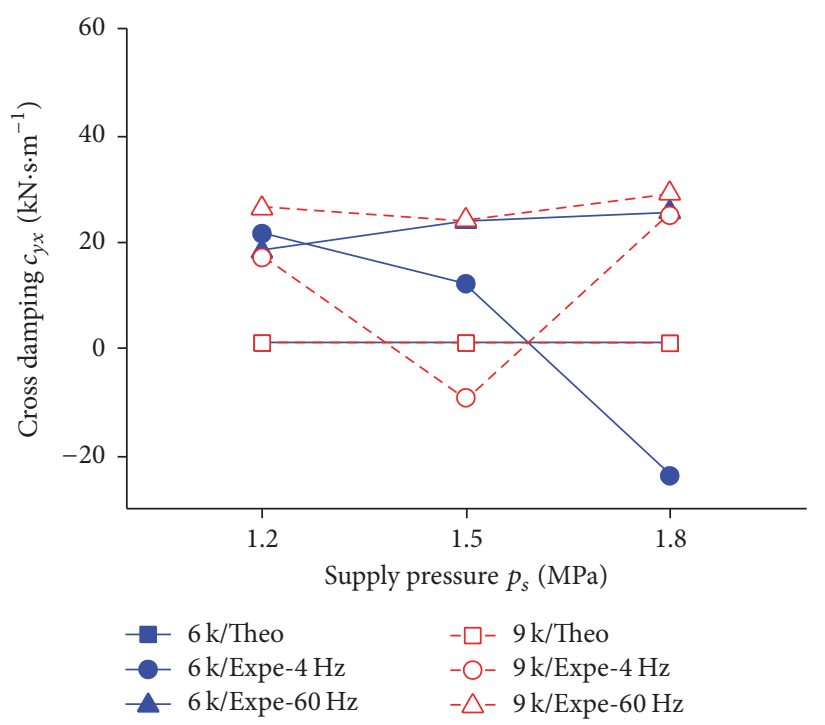

(c) Cross damping, $c_{y x}$

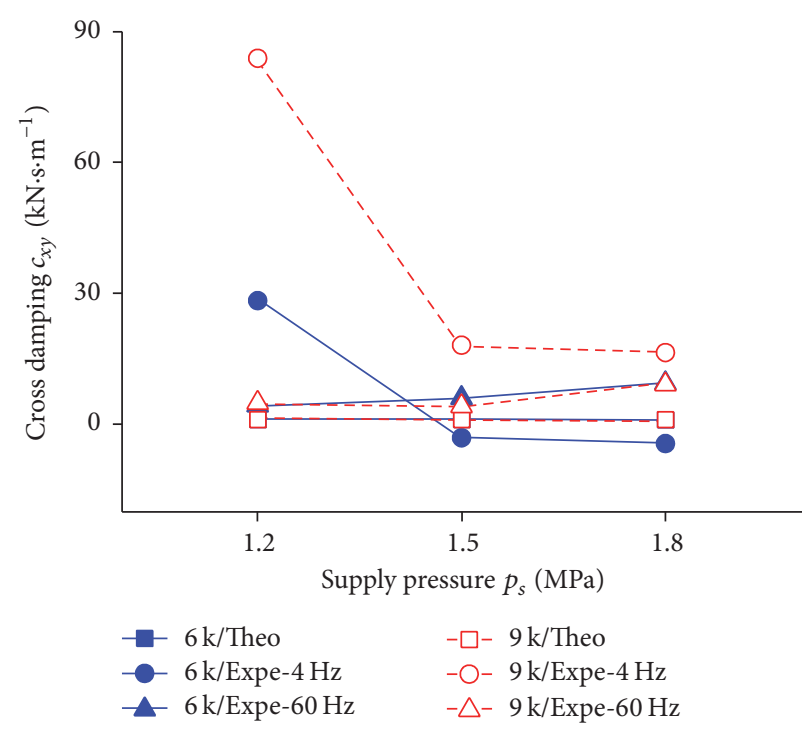

(b) Cross damping, $c_{x y}$

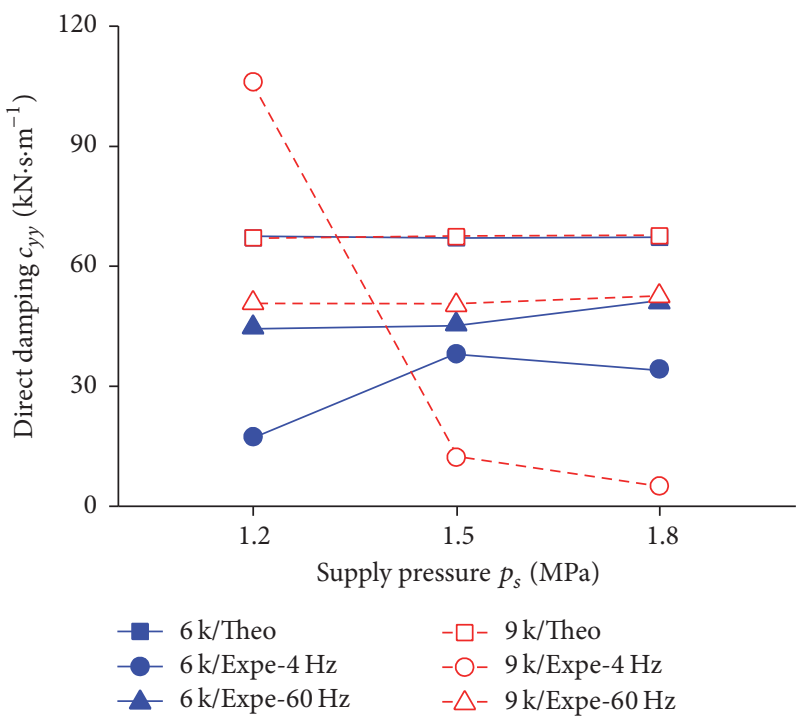

(d) Direct damping, $c_{y y}$

FIGURE 5: Comparative results of the damping coefficients by noncontact harmonic excitation: two rotating speeds (6,000 r/min and 9,000 r/min), three supply pressures (1.2 MPa, 1.5 MPa, and 1.8 MPa), and two exciting frequencies (4 Hz and $60 \mathrm{~Hz}$ ).

by phase errors and amplitude errors of journal vibration. The damping terms are usually more sensitive to phase errors of journal vibration than the stiffness terms. However, phase errors are very difficult to totally eliminate, especially for the additional unbalance excitation method, and amplitude errors of journal vibration may also exist in this study. Due to the compact structure of spindle, the space for adjustment of displacement sensors is limited in the test, so the displacement sensors are fixed and adjusted with four simple adjustable holders. This makes the precise relative position between the sensor and shaft difficult to determine, and the measured displacements can not reflect the actual journal vibration. Thus, phase errors and amplitude errors of vibration displacement are brought into the identification process during the measurement. In order to improve the results accuracy, the spindle design and the operation procedure are needed to optimize.

\section{Conclusions}

This study identifies the dynamic coefficients of high-speed water-lubricated hybrid bearings with circumferential grooves and stepped recesses. The noncontact harmonic excitation method and the additional unbalance excitation method are applied for different conditions, respectively. 


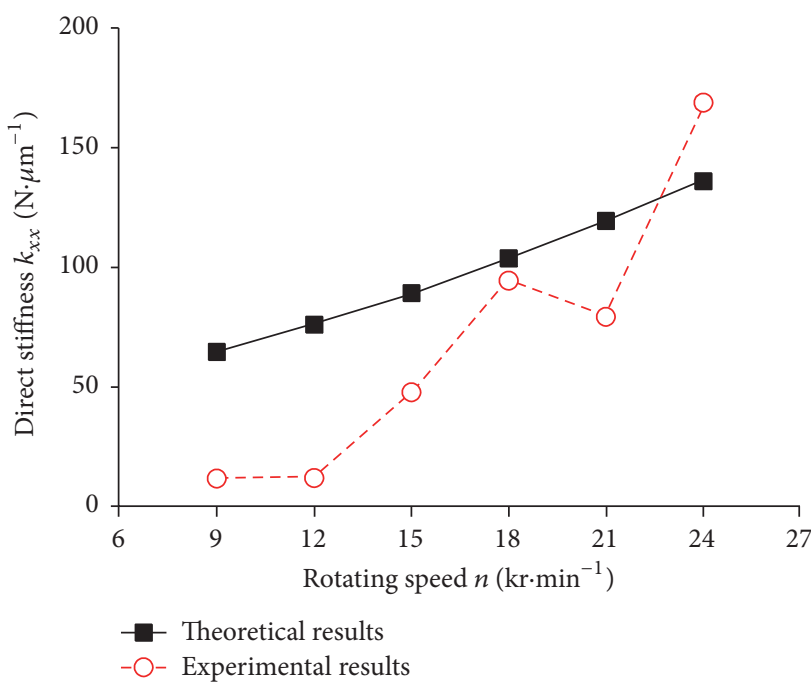

(a) Direct stiffness, $k_{x x}$

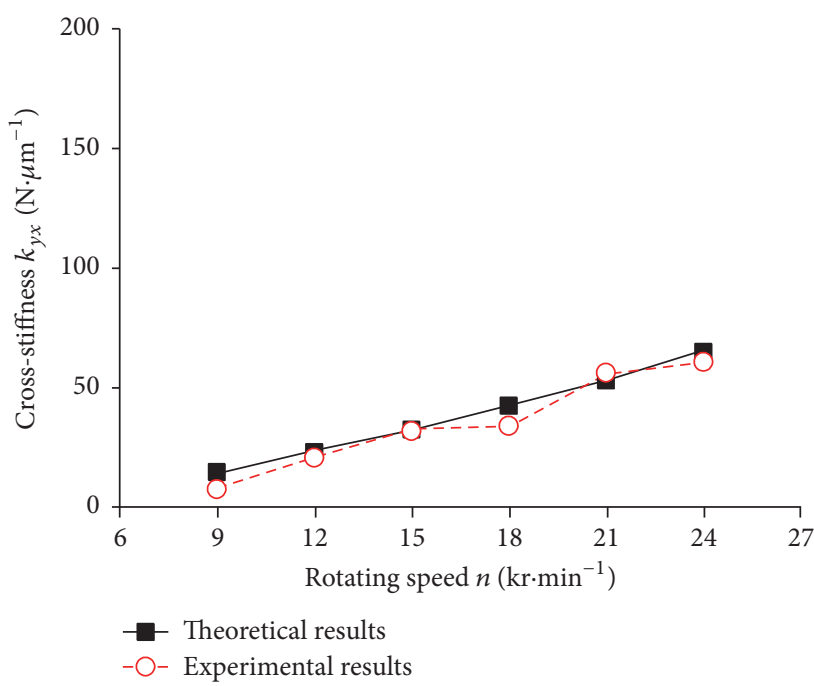

(c) Cross stiffness, $k_{y x}$

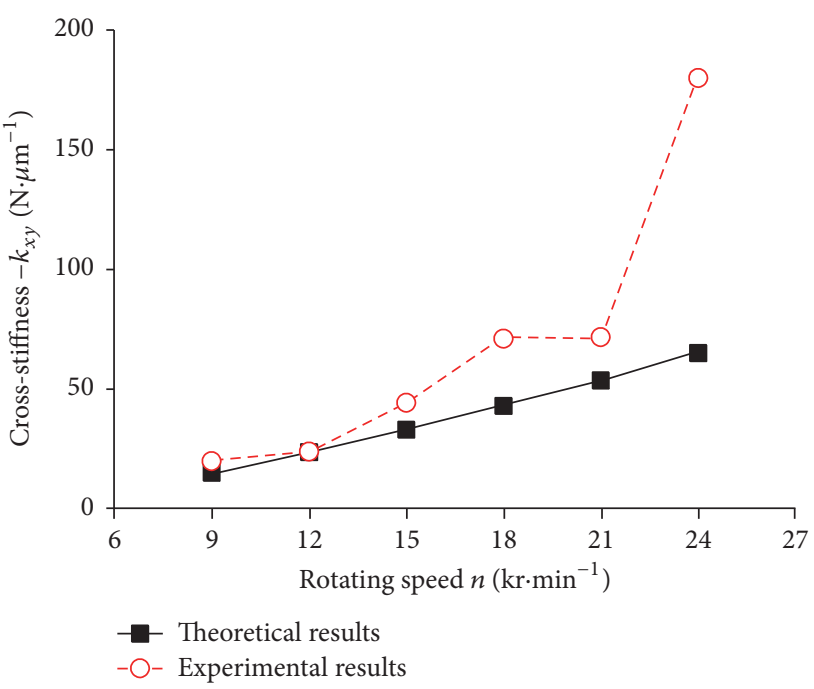

(b) Cross stiffness, $k_{x y}$

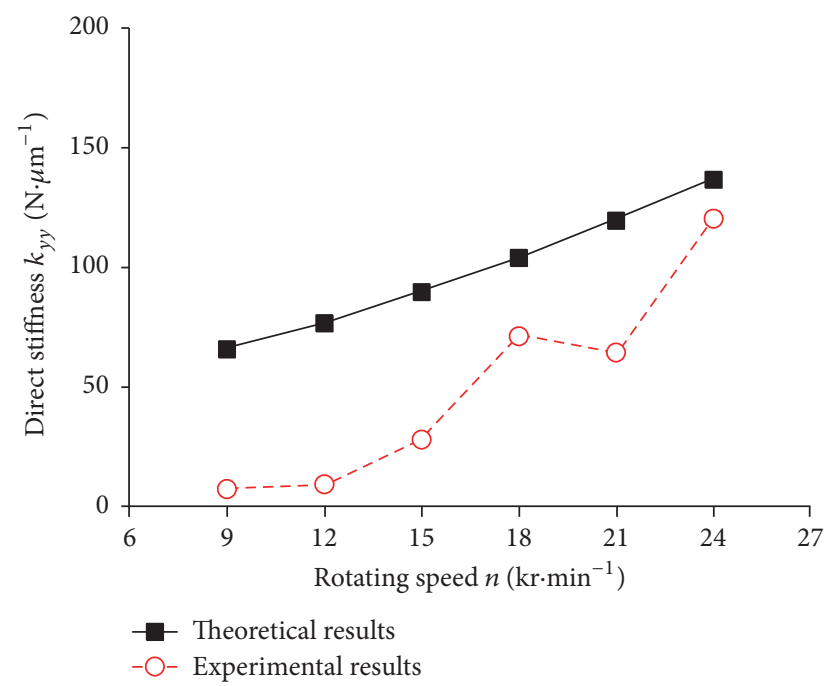

(d) Direct stiffness, $k_{y y}$

Figure 6: Comparative results of the stiffness coefficients by additional unbalance excitation: one water supply pressure (2.5 MPa) and six journal rotating speeds $(9,000 \mathrm{r} / \mathrm{min}$ to $24,000 \mathrm{r} / \mathrm{min})$.

The results indicate that the direct stiffness coefficients and the direct damping coefficients increase with rotating speed, which is helpful to improve the rotor stability and rotation accuracy. The direct stiffness coefficients increase with water supply pressure while the direct damping coefficients do not. Thus, there is no need to use too large water supply pressure during design and operation. A moderate water supply pressure can provide operation safety and cost economics.

When using the noncontact harmonic excitation method, experimental results of $60 \mathrm{~Hz}$ condition agree better with theoretical results. Thus, a higher excitation frequency is preferred to get better results for bearing coefficients identification.
The additional unbalance excitation is a useful method for ultra-high-speed conditions, but considerable care is needed for phase errors and amplitude errors of journal vibration, which are significant to improve the results accuracy.

\section{Conflicts of Interest}

The authors declare that they have no conflicts of interest.

\section{Acknowledgments}

This project is supported by National Natural Science Foundation of China [Grants nos. 51505384 and 51575421]. 


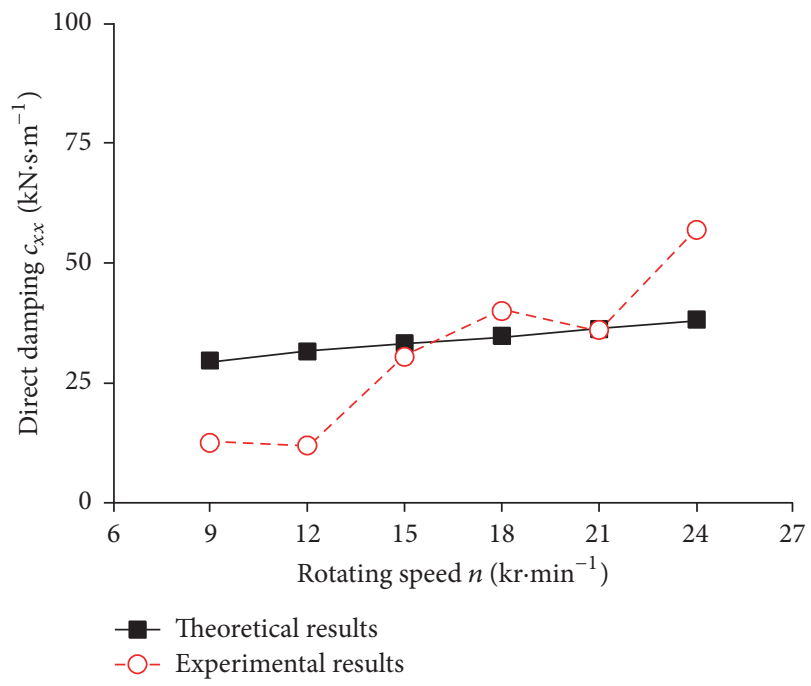

(a) Direct damping, $c_{x x}$

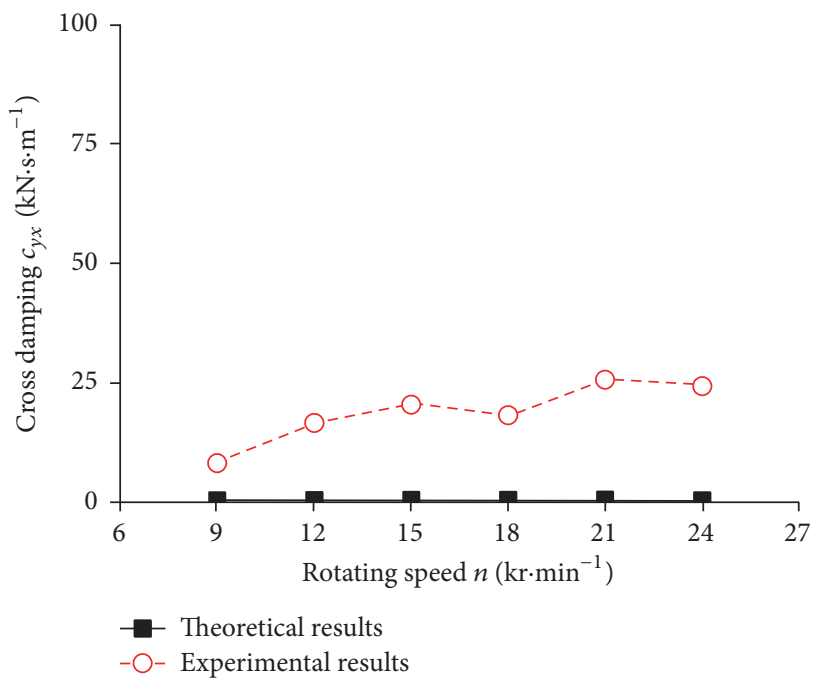

(c) Cross damping, $c_{y x}$

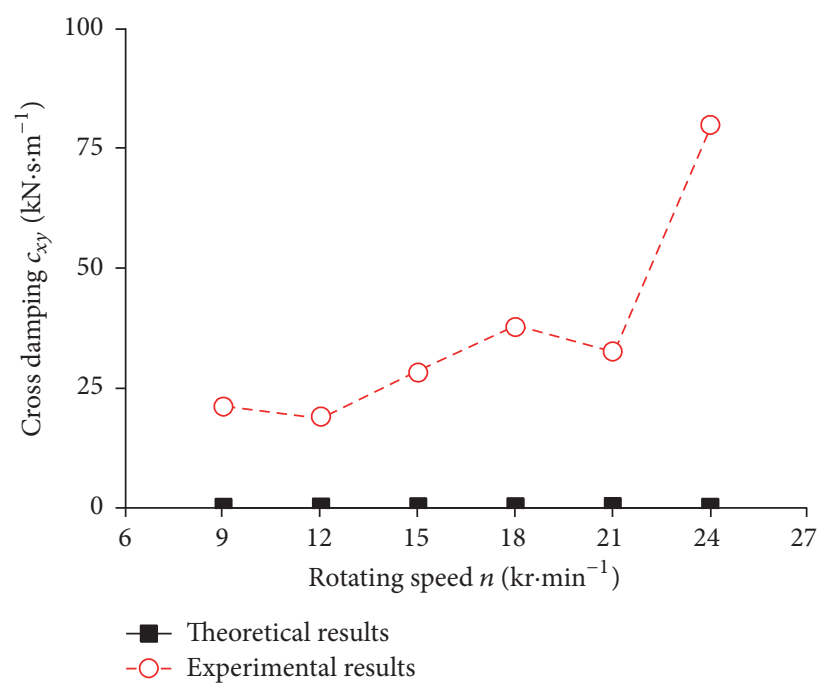

(b) Cross damping, $c_{x y}$

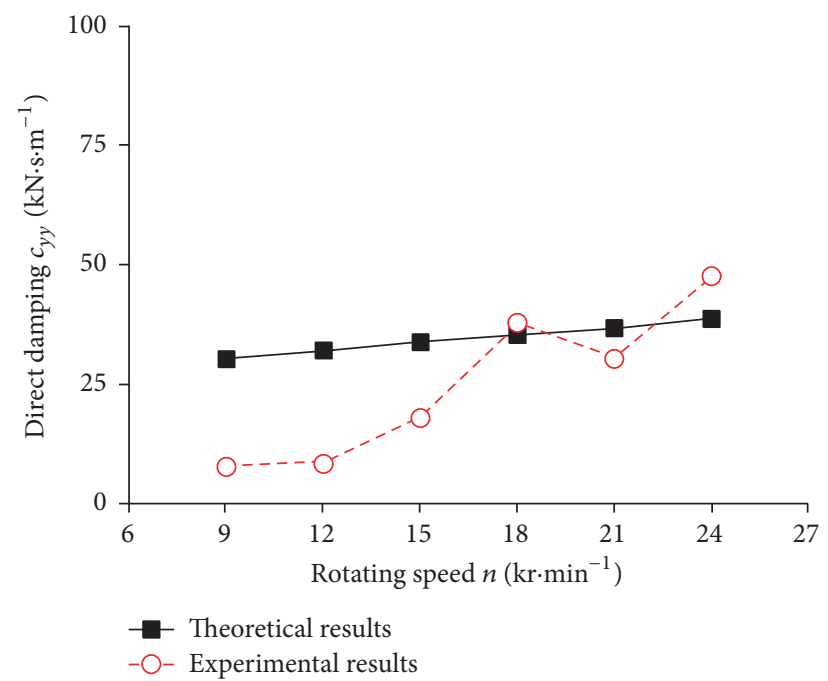

(d) Direct damping, $c_{y y}$

FIGURE 7: Comparative results of the damping coefficients by additional unbalance excitation: one water supply pressure ( $2.5 \mathrm{MPa})$ and six journal rotating speeds $(9,000 \mathrm{r} / \mathrm{min}$ to $24,000 \mathrm{r} / \mathrm{min})$.

\section{References}

[1] D. Chen, J. Fan, and F. Zhang, "Dynamic and static characteristics of a hydrostatic spindle for machine tools," Journal of Manufacturing Systems, vol. 31, no. 1, pp. 26-33, 2012.

[2] A. Hu, L. Hou, and L. Xiang, "Dynamic simulation and experimental study of an asymmetric double-disk rotor-bearing system with rub-impact and oil-film instability," Nonlinear Dynamics, vol. 84, no. 2, pp. 641-659, 2016.

[3] L. S. Andres, "Turbulent hybrid bearings with fluid inertia effects," Journal of Tribology, vol. 112, no. 4, pp. 699-707, 1990.

[4] M. Amine Hassini, M. Arghir, and M. Frocot, "Comparison between numerical and experimental dynamic coefficients of a hybrid aerostatic bearing," Journal of Engineering for Gas Turbines and Power, vol. 134, no. 12, Article ID 122506, 2012.

[5] L. Wang, S. Pei, X. Xiong, and H. Xu, "Investigation of the combined influence of turbulence and thermal effects on the performance of water-lubricated hybrid bearings with circumferential grooves and stepped recesses," Proceedings of the Institution of Mechanical Engineers Part J: Journal of Engineering Tribology, vol. 228, no. 1, pp. 53-68, 2014.

[6] A. Zhu, P. Li, Y. Zhang, W. Chen, and X. Yuan, "Influence of particles on the loading capacity and the temperature rise of water film in ultra-high speed hybrid bearing," Chinese Journal of Mechanical Engineering, vol. 28, no. 3, pp. 541-548, 2015.

[7] H. Feng and S. Jiang, "Dynamic analysis of water-lubricated motorized spindle considering tilting effect of thrust bearing," Proceedings of the Institution of Mechanical Engineers, Part C: Journal of Mechanical Engineering Science, 2016.

[8] S. Yoshimoto, T. Kume, and T. Shitara, "Axial load capacity of water-lubricated hydrostatic conical bearings with spiral grooves for high speed spindles: comparison between rigid and complaint surface bearings," Tribology International, vol. 31, no. 6, pp. 331-338, 1998. 
[9] S. Yoshimoto, S. Oshima, S. Danbara, and T. Shitara, "Stability of water-lubricated, hydrostatic, conical bearings with spiral grooves for high-speed spindles," Journal of Tribology, vol. 124, no. 2, pp. 398-405, 2002.

[10] L. Wang and H. Xu, "Experimental study on the dynamic performance of a new high-speed spindle supported by waterlubricated hybrid bearings," Shock and Vibration, vol. 2016, Article ID 8297834, 2016.

[11] N. M. Franchek, D. W. Childs, and L. San Andres, "Theoretical and experimental comparisons for rotordynamic coefficients of a high-speed, high-pressure, orifice-compensated hybrid bearing," Journal of Tribology, vol. 117, no. 2, pp. 285-290, 1995.

[12] T. W. Dimond, P. N. Sheth, P. E. Allaire, and M. He, "Identification methods and test results for tilting pad and fixed geometry journal bearing dynamic coefficients-a review," Shock and Vibration, vol. 16, no. 1, pp. 13-43, 2009.

[13] L. Wang, S. Pei, X. Xiong, and H. Xu, "Study on the static performance and stability of a water-lubricated hybrid bearing with circumferential grooves and stepped recesses considering the influence of recess sizes," Tribology Transactions, vol. 57, no. 1, pp. 36-45, 2013.

[14] H. Zhou, S. Zhao, H. Xu, and J. Zhu, "An experimental study on oil-film dynamic coefficients," Tribology International, vol. 37, no. 3, pp. 245-253, 2004.

[15] G. D. Jiang, H. Hu, W. Xu, Z. W. Jin, and Y. B. Xie, "Identification of oil film coefficients of large journal bearings on a full scale journal bearing test rig," Tribology International, vol. 30, no. 11, pp. 789-793, 1997.

[16] C.-C. Fan and M.-C. Pan, "Fluid-induced instability elimination of rotor-bearing system with an electromagnetic exciter," International Journal of Mechanical Sciences, vol. 52, no. 4, pp. 581-589, 2010.

[17] A. El-Shafei and A. S. Dimitri, "Controlling journal bearing instability using active magnetic bearings," Journal of Engineering for Gas Turbines and Power, vol. 132, no. 1, Article ID 012502, 2010.

[18] S. Ma, S. Pei, L. Wang, and H. Xu, "A novel active online electromagnetic balancing method-principle and structure analysis," Journal of Vibration and Acoustics, vol. 134, no. 3, Article ID 034503, 2012.

[19] H. P. Viveros and R. Nicoletti, "Lateral vibration attenuation of shafts supported by tilting-pad journal bearing with embedded electromagnetic actuators," Journal of Engineering for Gas Turbines and Power, vol. 136, no. 4, Article ID 042503, 2014.

[20] A. Matsubara, S. Tsujimoto, and D. Kono, "Evaluation of dynamic stiffness of machine tool spindle by non-contact excitation tests," CIRP Annals-Manufacturing Technology, vol. 64, no. 1, pp. 365-368, 2015.

[21] P. Arumugam, S. Swarnamani, and B. S. Prabhu, "Experimental identification of linearized oil film coefficients of cylindrical and tilting pad bearings," in Proceedings of the ASME International Gas Turbine and Aeroengine Congress and Exposition, V005T14A012, American Society of Mechanical Engineers, 1994.

[22] D. Sudheer Kumar Reddy, S. Swarnamani, and B. S. Prabhu, "Experimental investigation on the performance characteristics of tilting pad journal bearings for small L/D ratios," Wear, vol. 212, no. 1, pp. 33-40, 1997.

[23] B. Bediz, E. Korkmaz, and O. Burak Ozdoganlar, "An impact excitation system for repeatable, high-bandwidth modal testing of miniature structures," Journal of Sound and Vibration, vol. 333, no. 13, pp. 2743-2761, 2014.
[24] B. Bediz, B. Arda Gozen, E. Korkmaz, and O. Burak Ozdoganlar, "Dynamics of ultra-high-speed (UHS) spindles used for micromachining," International Journal of Machine Tools and Manufacture, vol. 87, pp. 27-38, 2014.

[25] A. K. Tieu and Z. L. Qiu, "Identification of sixteen dynamic coefficients of two journal bearings from experimental unbalance responses," Wear, vol. 177, no. 1, pp. 63-69, 1994.

[26] L. Wang, X. Xiong, and H. Xu, "Non-contact electromagnetic exciter design with linear control method," Chinese Journal of Mechanical Engineering, vol. 30, no. 1, pp. 135-143, 2017. 


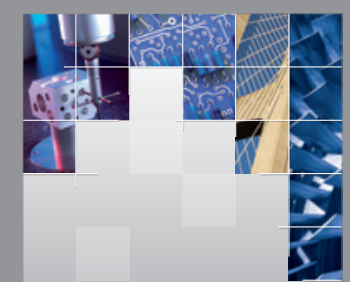

\section{Enfincering}
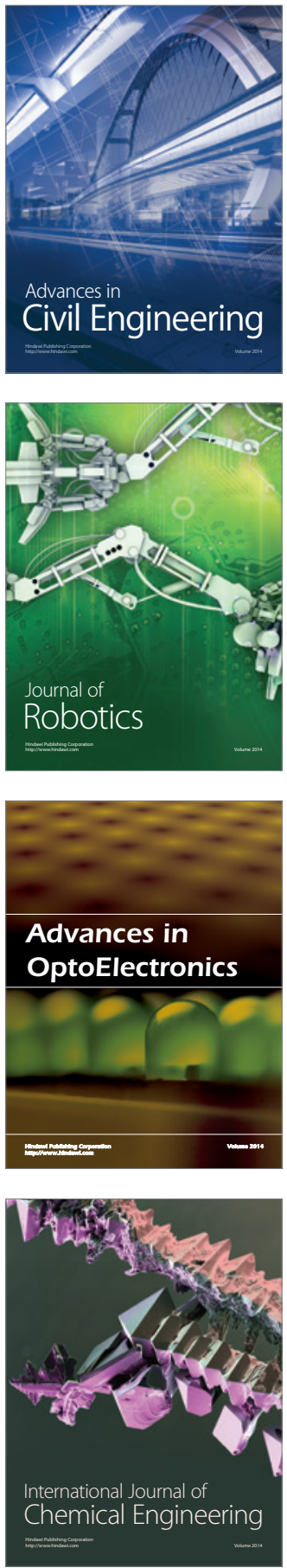

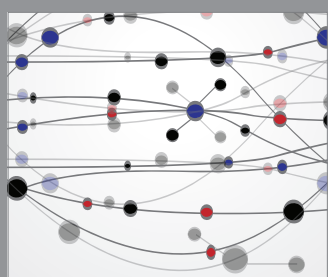

The Scientific World Journal

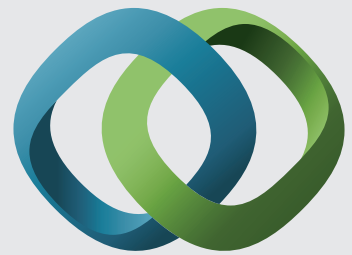

\section{Hindawi}

Submit your manuscripts at

https://www.hindawi.com
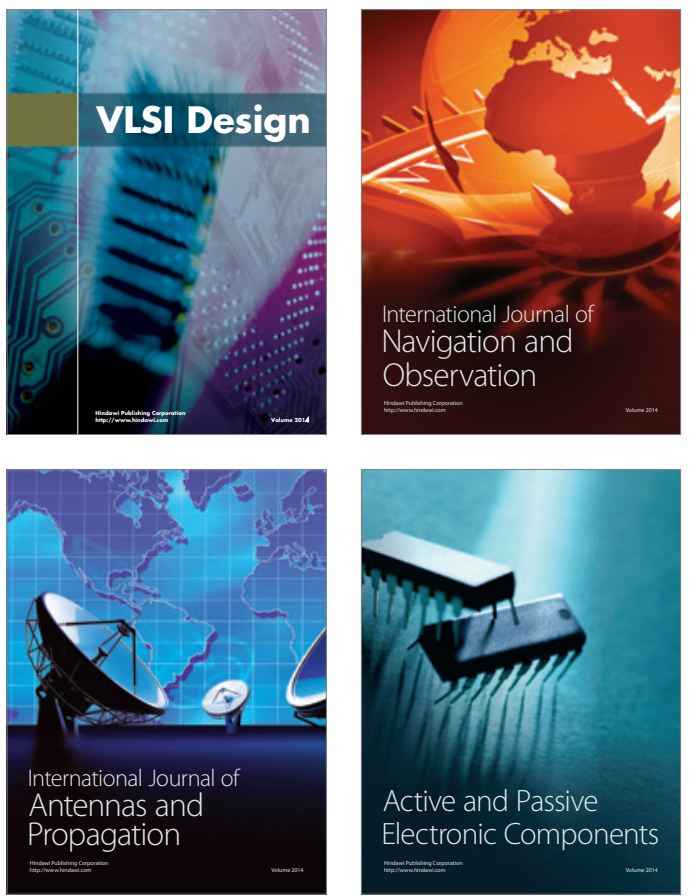
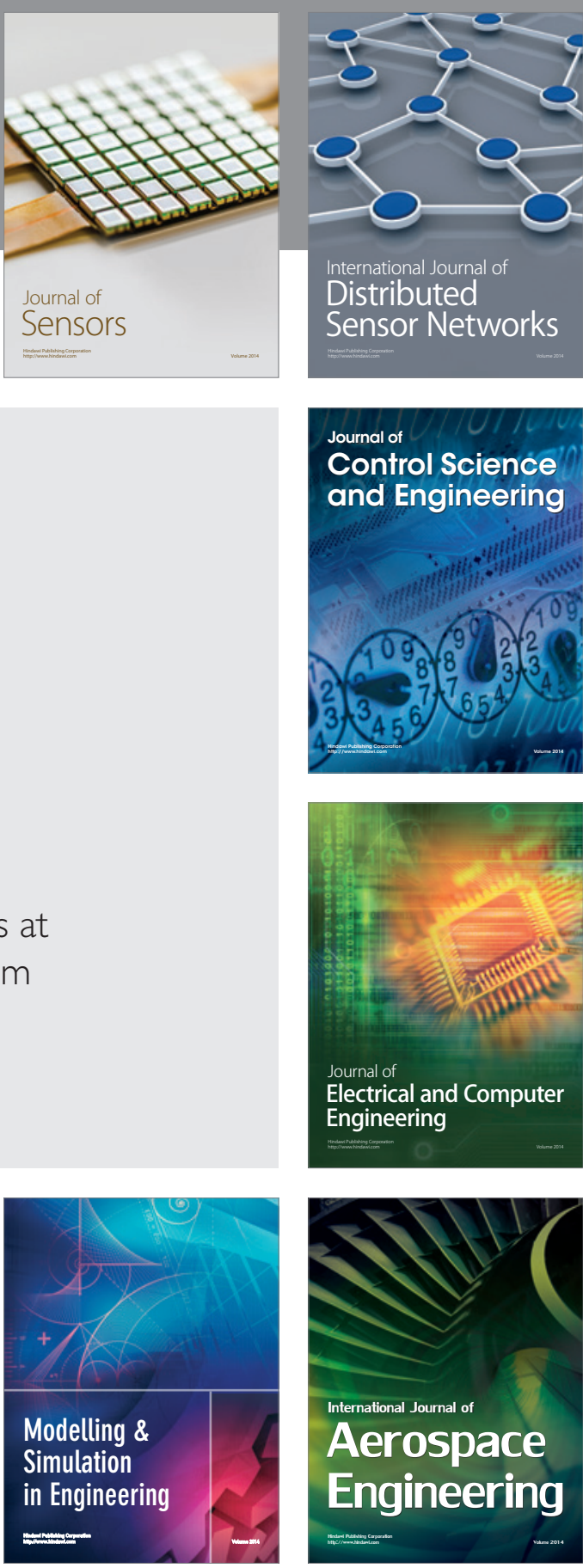

International Journal of

Distributed

Sensor Networks

$-$

Joumal of

Control Science

and Engineering
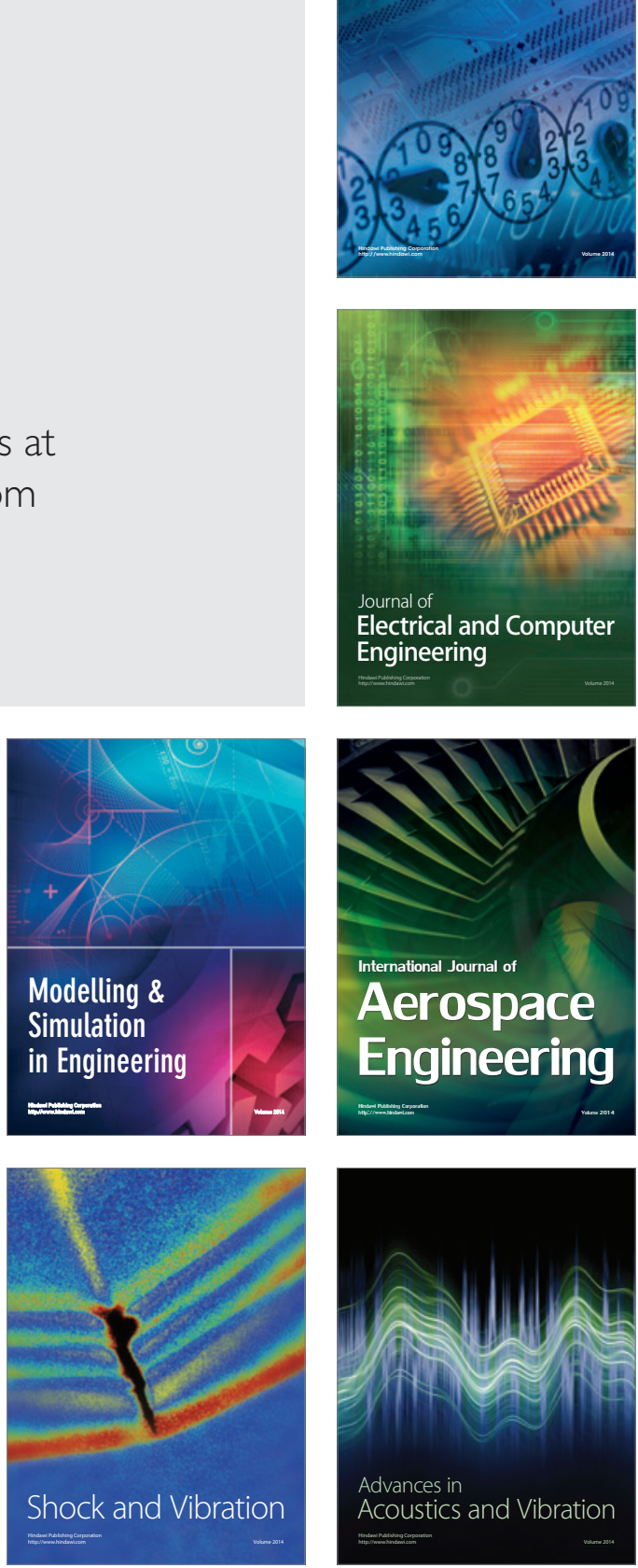